\title{
Germanizmi v frazemih Slovarja slovenskega knjižnega jezika od M do P
}

\author{
Irena Stramluič BreZnik \\ Univerza v Mariboru, Filozofska fakulteta, Koroška cesta 160, \\ SI-2000 Maribor,irena.stramljic@uni-mb.si
}

\begin{abstract}
SCN II/2 [2009], 63-74
Prispevek obravnava v Slovar slovenskega knjižnega jezika sprejete germanizme od M do P, ki so hkrati tudi frazemske sestavine. S pomočjo referenčnega korpusa Fidaplus se ugotavlja živost takih frazemov v sodobni rabi in posledično odgovarja na vprašanje, koliko in katere tovrstne frazeme je smiselno upoštevati tudi v novi izdaji slovarja slovenskega jezika.

This article examines the Germanisms included in the Dictionary of Slovene Literary Language (SSKJ) from $\mathrm{M}$ to $\mathrm{P}$ which are also idiom ingredients. With the support of the reference corpus Fidaplus, presence in contemporary use is stated, and, consequently, answers to the questions how many and what kind of idioms would be reasonable to take into account in the new issue of the Dictionary of Slovene are suggested.
\end{abstract}

Ključne besede: leksikologija, frazeologija, frazemi, germanizmi, slovar

Key words: Lexicology, Phraseology, Idioms, Germanisms, Dictionary

\section{Uvod}

0.1 Za sleherni frazeološki fond jezika velja, da ga sestavljata dve temeljni skupini frazemov. Prvo sestavljajo frazemi, ki so nastali v jeziku samem in izražajo specifične pomene. Pogosto namreč temeljijo na folklornih in nacionalnih motivih ter odslikavajo podatke o narodovem kulturnem in materialnem življenju. Drugo pa sestavljajo frazemi, ki so iz različnih jezikov v različnih časovnih obdobjih prihajali $\mathrm{v}$ jezik in se tam tudi ustalili, bodisi v izvorni citatni obliki (ad acta, enfant terrible) ali kot kalki (nem. von Hand zu Hand, angl. from hand to hand, hr. iz ruke u ruku, slov. iz roke v roko) in tvorijo t. i. mednarodno frazeologijo, ki ima lahko antični (Ahilova peta, Damoklejev meč), 
biblijski izvor (nejeverni Tomaž, Sodoma in Gomora) ali se širi s prevajanjem književnih (človek zver (Zola)) in drugih del (Menac 2007: 109-123).

Domače in prevzeto vselej sobiva v vseh jezikovnih segmentih, torej tudi frazeološkem. Na podlagi jezikovnih, zgodovinskih in kulturnih dejstev pa lahko ugotavljamo, kakšno je trenutno razmerje med njima, kateri del postaja aktivnejši in kateri pasivnejši v rabi (Fink, Menac 2008: 88-100). Premislek o frazemih, katerih sestavina je germanizem, je s tega stališča upravičen tudi v slovenščini. Ker me zanima le živost tovrstnih frazemov v sodobni jezikovni rabi, ki naj bi jo prikazovala tudi nova izdaja slovarja slovenskega jezika (Stramljič Breznik 2009), prispevek nima namere odkrivati, ali je germanizem v frazemu zgolj gostujoč sestavinski element (glasovalna mašina) ali gre v celoti za iz nemščine kaliran frazem (imeti maslo/puter na glavi, prim. Butter auf dem Kopf haben).

0.2 Germanizmi so posledica jezikovnega vplivanja nemščine na slovenščino, ki je trajalo neprekinjeno več kot tisoč let, vse do prve svetovne vojne s ponovnimi poskusi načrtne germanizacije tudi v času druge svetovne vojne. Ves čas pa je severna jezikovna meja ohranjala fizični stik med obema jezikoma, ki ni bil nikoli prekinjen (Stramljič Breznik 2004).

Germanizmi (Toporišič 1992: 299-300) so kategorija iz nemščine prevzetih besed (Toporišič 2006: 62-63), ki so docela prilagojeni zgradbenim lastnostim slovenskega jezika, saj jih je prevzelo ljudstvo na podlagi govornega prenosnika (Snoj 2006: 346), vendar v knjižno normo niso sprejeti. S tega stališča je razumljivo, da je Slovar slovenskega knjižnega jezika, ki jezik prikazuje z vidika zvrstne členjenosti, tj. jezik prikazuje kot sestav, ki ima za vse uporabnike veliko stalnega, skupnega, toda hkrati tudi prvine, ki so v rabi omejene, vključeval tudi germanizme, ker jih je raba na podlagi kartotečnega gradiva potrjevala v dovolj veliki pogostnosti, čeprav precejšen njihov del ni bil sprejet v leksikalni sistem knjižnega jezika. Na to opozarjajo pripadajoči jim stilno-plastni, časovno-frekvenčni ali ekspresivni kvalifikatorji. V njih je mogoče prepoznati prvine purizma, ki določene sestavine označuje kot bolj ali manj zaželene ter preprečuje vstop nižjepogovornim in drugim neknjižnim prvinam v knjiži jezik (Kalin Golob 2008: 17).

\section{Germanizmi kot frazeološke sestavine}

1.0 Germanizmi kot tip prevzetega izrazja so bili v slovenistiki pogosto omenjani kot prvine narečja ali pogovornega jezika, posebej natančno pa so bili besedni germanizmi (Toporišič 1988: 109-119) oz. nemške izposojenke (Jazbec 2007) obdelane tudi pri Trubarju. ${ }^{1}$ Mogoče se je strinjati s trditvijo (Topori-

${ }^{1}$ Glede na gradivni obseg prispevka je zanimivo predstaviti, katere nemške korene, osnove ali podstave od $m$ do p navajata oba avtorja. Toporišič (1998: 109): mahtig, mal-, martr-, mas-, menih, merk-, nid, nuc-, obar-, ofr-, ofert-, papež, paradiž, pekel, persona, petler-, 
šič 2006: 70), »da prevzete in neprevzete besede kakega jezika tvorijo precej nerazdeljivo jezikovno celoto«. To misel je mogoče ponazoriti z naslednjim nizom iz nemščine prevzetih besed, ki jim je etimološko mogoče dokazovati prevzetost, toda njihova stilna vrednost je zelo raznolika. SSKJ in SP 2001 jih namreč s stališča zaznamovanosti različno razvrščata:

(1) brez kvalifikatorja v obeh priročnikih: porcelan $<$ nhd. Porzellan $<$ it. porcellana (ST, 198; ESSJ III, /; SES, 546);

(2) knjiž./neobč., raj: paradiž < mhd. paradis, paradise (ST, 189; ESSJ III, 9; SES, 492);

(3) pog./knjiž.pog. |duševno bolan|: nor < bair.-öster. Narr, kärnt. narre, noar, nor 'Narr' (ST, 184; ESSJ III, 227; SES, 450);

(4) pog./knjiž. pog., redovnica: nuna < ahd. nunna: mhd. nunne, nonne; nhd. Nonne (ST, 184; ESSJ III, 230; SES, 453);

(5) nižje pog./neknj. ljud., potrebovati, rabiti: nucati < mhd. nützen, nutzen 'gebrauchen, benutzen' (ST, 184; ESSJ III, 229; SES, 453).

Glede na opredelitev germanizmov v Enciklopediji slovenskega jezika (Toporišič 1992: 47) so v najširšem smislu (pomen 2) germanizmi vse besede od 1 do 5. Germanizma, ki v knjižni sistem nista sprejeta (pomen 1), pa sta potemtakem le besedi 4 in 5 . Njuna raba je v knjižnem jeziku manj primerna, saj so jima pripisane nevtralne domače sopomenke. Posebno vprašanje sproža primer 3, beseda je zaznamovana v SSKJ kot pogovorna, njena nevtralna sopomenka je lahko tretji pomen besede neumen. Obe značilnosti ju uvrščata bliže spodnjemu kot zgornjemu tipu iz nemščine prevzetih besed. Zdi pa se, da je beseda že globoko vraščena v slovenski leksikalni sistem, njenega izvora povprečni uporabnik jezika ne bi več povezoval z nemščino. Na to pa kaže tudi njen socialnozvrstni premik iz pogovorne besede (SSKJ) v knjižno pogovorno (SP: vendar brez dodane sopomenke, v pokončnih oklepajih je naveden le približni pomen).

1.1 Pričujoči prispevek, ki je nadaljevanje raziskave o germanizmih kot sestavinah slovenskih frazemov (Stramljič Breznik 2007: 291-303 in 2007a: 459-473), upošteva v obeh delih postavljeno merilo, da so zajeti le tisti germanizmi, ki so v leksikalnem sistemu že brez podrobnejšega etimologiziranja prepoznani kot nevraščeni.

Zaradi primerljivosti rezultatov je ohranjen enak metodološki pristop. Na podlagi potrjenih nemških izposojenk v slovenščini (Striedter-Temps 1963; ST) in njihovih razlag v obeh etimoloških slovarjih slovenskega jezika Franceta Bezlaja (1977-2007; ESSJ) in Marka Snoja (2003; SES), je bila preverjena njihova vključenost v gradivo SSKJ. Ker je takih izposojenk v slovenščini zelo veliko, sta bila določena omejitvena kriterija: (1) Beseda je po izvoru germanizem, ki

pild, pridig-. Jazbečeva (2007: 55-66) pa besede: maiefteta, maninga, marin, martra/ martrnik/-ica,/martrati, maffa, menih, merdar, moister, muia, myto, norroft/nor(r)/ norski, nuna, nuz/nuzati, nyd/nid/nidati/nydati, obrupati, offer/offrati, offert/offerten, ordninga, papesh, pehar, petlati, pild, poft/poftiti se, pridiga, pint, purgar. 
pa še ni vraščen v nevtralno leksiko slovenskega jezika, saj to kaže kateri od kvalifikatorjev, mašina pog. < nhd. Maschine < franz. machine, lat. machina (ST, 178; ESSJ II,/; SES, 384). (2) Beseda je sestavina frazema (glasovalna mašina pog., slabš. 'vse, kar v zvezi z volitvami, glasovanjem dela kaka skupina za svojo zmago').

Pri tem sem bila posebej pozorna na to, ali taka iztočnica v svojem geselskem članku vsebuje frazem v predvidenem frazeološkem gnezdu (oznaka pred tako iztočnico je 1); iztočnica v svojem geselskem članku vsebuje frazem, vendar ne v predvidljivem frazeološkem gnezdu (oznaka 2) in iztočnica je brez sicer vsaj meni znanega frazema (oznaka 3).

Glede na sedanje aktualno terminološko stanje uporabljam izraz frazem. Kot definicijske lastnosti frazemov upoštevam tradicionalna merila: reproduciranost, najmanj dvobesednost (Kržišnik 1994), ki vključuje tudi tip minimalnih frazemov (tj. takih s strukturo glagola in predložnega prostega morfema ali glagola in zaimenskega prostega morfema v klitični obliki (Kržišnik 2005) ter tudi t. i. dvojčiče raznih tipov (Toporišič 1996)), neizpeljivost pomena iz pomena sestavin, stalnost ter ekspresivnost. Vključeni so tudi nekateri primeri pregovorov, ki sicer ne sodijo v ožje področje frazeologije, določeno s prej naštetimi definicijskimi lastnostmi. Pri gradivu frazemov sem izhajala iz SSKJ, dopolnilna vira sta poskusni frazeološki slovar (Keber 2003; K) in korpus slovenskega jezika Fidaplus (F+).

\section{Germanizmi v frazemih SSKJ od M do P v korpusu Fidaplus}

2.1 Germanizmi so zapisani po abecedi tako, da je najprej označen tip iztočnice glede na vsebovanost frazema $\mathrm{v}$ SSKJ, iztočnica je izpisana krepko z velikimi črkami, dodane so osnovne slovnične lastnosti in pripisana slovarska kvalifikatorska oznaka. Prikazana je prevzetost iz nemščine na podlagi tujih in domačih etimoloških virov. Izpisan je ustrezni frazem iz frazeološkega gnezda ali ponazarjalno gradivo, če je v njem vsebovan frazem. V primeru, da frazema v geselskem članku ni, je dodan. Sledijo podatki o pojavitvah v referenčnem korpusu Fidaplus, in sicer celega ali ustreznega dela frazema s pripadajočimi zgledi, ki so izbrani tako, da kažejo tudi morebitno variantnost sestavin. Če ni posebnosti ali variantnosti, je navadno zabeležen le en zgled rabe.

\subsection{Abecedni prikaz}

(1) MALAR -ja m žarg. 'slikar' < ahd. malari, malon; mhd. malaere, maler, malen; nhd. Maler, malen (ST, 175; ESSJ III, 163: malati; SES, 375: malati). Označen frazeološki pomen v SSKJ: 
- pog., ekspr. vsake oči imajo svojega malarja 'vsakdo ima drugačna lepotna merila, drugačen okus';

F+: vsake oči imajo svojega malarja (179 pojavitev): Glede oblike imajo vsake oči svojega malarja, barvo pa ponavadi določa cena. - Pravijo, da imajo vsake oči svojega malarja.

(1) MALHA -e ž 1. nekdaj 'preprosta popotna torba za čez ramo' < ahd. malha, malha; mhd. malhe 'Ledertasche, Mantelsack' (ST, 175; ESSJ III, 163; SES, 375).

Označen frazeološki pomen v SSKJ:

- ekspr. preg. vsak berač svojo malho hvali 'vsakdo hvali svoje';

$\mathrm{F}+$ : vsak berač svojo malho hvali (15 pojavitev): Ker pa vsak berač svojo malho hvali, mislim, da je ljubljanska univerza kljub množici ... - "Vsak berač svojo malho hvali, "si je rekel Zmago Sagadin in ...

(1/3) MARELA -e ž nižje pog. 'dežnik' < avstr. nem. Amrel < it. ombrello 'dežnik, sončnik' (ST, /; ESSJ III, 167; SES, 380).

Označen frazeološki pomen v SSKJ:

- pog., ekspr. ženi se pod marelo 'ne da bi imel zagotovljeno bivališče'; pog. zgodba je napeta kot marela 'zelo napeta';

$\mathrm{F}+$ : ženiti se pod marelo (0 pojavitev);

F+: napet kot marela (7 pojavitev): Nenavadno žrebanje je bilo napeto kot marela. - Napeto bo »kot marela», o tem so prepričani vsi.

Manjkajoči frazeološki pomen v SSKJ:

$\mathrm{F}+$ : važen kot marela (1 pojavitev): ... so marširali skozi prostore in oddaje nacionalne televizije, važni kot marele in prepričani, da se svet vrti prav zaradi njih.

(2) MARNJA -e ž nav. mn., ekspr., raba peša 'neresnična vest, izmišljotina' < stvn. mari 'govorica, pravljica'; srvn. maere 'govorica, sporočilo'; nvn. dial. maeren, marn 'govoriti, klepetati' (ST, /; ESSJ III, 167; SES, 382).

Neoznačen frazeološki pomen v SSKJ:

babje, škodoželjne marnje; to so prazne marnje 'vsebinsko prazno govorjenje'; $\mathrm{F}+$ : biti/ne biti kaj prazne marnje (158 pojavitev): To niso nobene prazne marnje.

$\mathrm{F}+$ : biti/ne biti kaj babje marnje (4 pojavitve): Le da je iz njih spravljal le, oprostite, babje marnje.

(1) MARTRA -e ž star. 'trpljenje, bolečina' < mhd. marter, martere, martel, mater Kruzifix, Qual, Pein, Folter', prim. bair.-öster. die Marter, 'Kreuz, Kruzifix’ (ST, 177; ESSJ III, 169; SES, /).

Označen frazeološki pomen v SSKJ:

- star. božja ali bridka martra 'križ s podobo Kristusa';

$\mathrm{F}+$ : bridka martra (0 pojavitev);

$\mathrm{F}+$ : božja martra (0 pojavitev). 
(1) MAŠINA -e ž 1. pog. 'stroj' < nhd. Maschine < fr. machine < lat. machina (ST, 178; ESSJ III, /; SES, 384).

Označen frazeološki pomen v SSKJ:

- pog., slabš. glasovalna mašina 'vse, kar v zvezi z volitvami, glasovanjem dela kaka skupina za svojo zmago';

F+: glasovalna mašina (8 pojavitev): Rezultat kaže, da je parlamentarna glasovalna mašina "porezala« enega kandidata ... - Trinajstmilijonska glasovalna mašina je na prvo mesto sklikala južnokalifornijske ...

(3) MEŽNAR -ja m pog. 'kdor oskrbuje cerkev; cerkovnik' < mhd. mesnaere, messenaere 'Küster' (ST, 179; ESSJ III, 183; SES, 399).

Manjkajoč frazeološki pomen v SSKJ, ki pa tudi ni korpusno potrjen: stati kot mežnar; 'nedejavno opazovati dogodek, pri katerem bi bila pričakovana, zaželena dejavnost';

$\mathrm{F}+$ : stati kot mežnar (0 pojavitev).

(1) MUJA -e ž raba peša 'trud, prizadevanje' < ahd. muoi, muoen; mhd. müeje 'Beschwerde, Mühe, Last, Not'; nhd. Mühe, mühen (ST, 181; ESSJ III, 205; SES, 423).

Označen frazeološki pomen v SSKJ:

- preg. brez muje se še čevelj ne obuje 'brez truda, prizadevanja ni pričakovati uspeha';

F+: brez muje se še čevelj ne obuje (123 pojavitev): Predvsem moraš biti pripravljen na sodelovanje, kajti brez muje se še čevelj ne obuje. - (primer prenovitve: Lev Kreft je v članku z naslovom Brez Muje se še Bosman ne obuje ...).

(1) NUCATI -am nedov. nižje pog. 1. 'potrebovati, rabiti'; 2. 'koristiti, pomagati' < mhd. nützen, nutzen 'gebrauchen, benutzen' (ST, 184; ESSJ III, 229; SES, 453). Označen frazeološki pomen v SSKJ:

- nižje pog. kaj bi si jezik nucal, saj ga ne prepričaš 'kaj bi govoril, si z govorjenjem prizadeval doseči'; nižje pog. fant, pamet nucaj, da ne bo narobe 'ravnaj, misli pametno, preudarno';

$\mathrm{F}+$ : jezik nucati (0 pojavitev);

F+: pamet nucati (1 pojavitev): Odgovor je na dlani! Delaj in pamet nucaj!

(1) NUNA -e ž 1. pog. 'članica samostanskega, verskega reda; redovnica' < ahd. nunna: mhd. nunne, nonne; nhd. Nonne (ST, 184; ESSJ III, 230; SES, 453). Označen frazeološki pomen v SSKJ:

- pog. iti $\boldsymbol{k}$ nunam 'postati redovnica';

F+: iti k nunam (1 pojavitev): ... nisi nobena ženska, še za v posteljo nisi, pojdi k nunam!«

(1) OFER ofra m nižje pog. 'dajanje denarja za cerkvene potrebe, včasih v zvezi s sprevodom vernikov okoli oltarja' < srvnem. opfern, stvnem. opfaron ‘žrtvovati' (SES, 465; ST, 185; ESSJ III, 242). 
Označen frazeološki pomen v SSKJ:

- star. dati komu ofer 'dar';

F+: dati komu ofer (1 pojavitev): Na Štajerskem so pravili, da je treba vancašu dati ófer (dar), če niso našli vode.

(1) PACA -e ž nižje pog. 'zmes zelenjave, začimb in kisa, v kateri se kvasi meso, navadno meso divjačine; kvaša < bav. nem. paizen, kar ustreza knjiž. nem. beizen 'lužiti', Beize 'lužilo' (SES, 485; ST, 187; ESSJ IV, 1).

Označen frazeološki pomen v SSKJ:

- nižje pog. imeti koga v paci 'pregovarjati ga, pridobivati ga; pogovarjati se o njem';

F+: imeti koga v paci (10 pojavitev): »Danes imam v paci še posebej zapleten primer, « se je opravičil. - Tudi v Ljubljani imajo v paci podobno akcijo, a v živalskem vrtu primanjkuje slonov.

(2) PANKRT -a m slabš. 'nezakonski otrok' < mhd. banchart, bankart 'Bastard' (ST, 188; ESSJ IV, 8; SES, 490).

Neoznačen frazeološki pomen v SSKJ:

kot psovka prekleti pankrt;

$\mathrm{F}+$ : prekleti pankrt (5 pojavitev): ... oglasi Kaja in ga gleda, besna, tak preklet pankrt si, Iztok. - /.../ je vila roke, češ, kakšno sramoto nam dela, prekleti pankrt.

(2) PARE par ž mn. pog. 'mrtvaški oder' < ahd.bair. para; ahd. bara; mhd. bare 'Sänfte, Bahre, Totenbahre' (ST, 189; ESSJ IV, 9; SES, 493).

Neoznačen frazeološki pomen v SSKJ:

položiti na pare; ležati na parah; ljudje so se zbrali ob parah;

F+: ležati na parah (17 pojavitev): Gospodar je še ležal na parah in vdova je bila napol otopela od žalosti. - Mislili smo, da ležite na parah, vi pa tule ... Kako to?

(1) PILDEK -dka m (i) iron. 'slika' < nem. Bildlein 'podobica' manjšalnica od Bild, bav. Pild 'podoba, kip' (SES, 514; ST, /; ESSJ IV, /).

Označen frazeološki pomen v SSKJ:

- ekspr. tak je kot žabji pildek narobe 'grd, neprikupen'.

$\mathrm{F}+$ : tak kot žabji pildek narobe (0 pojavitev).

(1/3) PLANKA -e ž 2. mn., pog. 'plot' < mhd. planke, blanke, v mn. 'Plankenzaun', nhd. Planke (ST, 195; ESSJ IV. 48; SES, 521).

Označen frazeološki pomen v SSKJ:

- pog. skakati čez planke 'čez plot' (nejasno slovarsko označen pomen le s sestavinsko varianto, ki kaže na pomen 'varati'); ekspr. videti travo rasti in slišati planke žvižgati 'videti in slišati stvari, ki jih v resnici ni’;

$\mathrm{F}+$ : slišati planke žvižgat (0 pojavitev); 
F+: (skakati/skočiti//pogledati/pokukati) čez planke (448 pojavitev; večinoma povezane z oddajo Čz planke): Prisiljeni bomo (po)gledati čez planke dlje kot le do soseda. - Včasih je vredno čez planke skočiti tudi z dobro knjigo.

Sestavini pogledati/pokukati frazemu lahko dajeta tudi drugačen pomen, nakazan tudi z besedilnim zgledom čez planke skočiti s knjigo, saj gre za pomen 'razgledati se, razširiti si meje vednosti', zato bi bilo smisleno ta pomen tudi na novo dodati.

(1) PLEH pleha m nižje pog. 'pločevina' < ahd. plëch, blëch; mhd. blëch; nhd. Blech (ST, 196; ESSJ IV, 53; SES, 525).

Označen frazeološki pomen v SSKJ:

- nižje pog., neskl. pril.: pleh muzika 'godba na pihala';

F+: pleh muzika (108 pojavitev): Za njim je stopala lokalna pleh muzika.

(1) PRANGER tudi prangar -ja m zgod., nekdaj 'steber, h kateremu postavljajo, privezujejo ljudi za kazen’ < srvn. pranger, branger, prenger, brangel; nvn. Pranger (ESSJ IV, 102; ST, /; SES, 558).

Označen frazeološki pomen v SSKJ:

- ekspr. $v$ romanu je avtor postavil na pranger tedanje meščane in njihovo moralo 'osramotil, osmešil';

$\mathrm{F}+$ : (postaviti/postavljati/dati/pribijati/privezati) na pranger (88 pojavitev): $V$ praksi so na prangerju seveda samo mlade muslimanke. - ... na ta način branijo zato, ker jih javnost postavlja na pranger.

(1) PUKEL -kla m nižje pog. 'grba' < bair.öster. Puckel, nhd. Buckel (ST, 203; ESSJ IV, 135; SES, 592).

Označen frazeološki pomen v SSKJ:

- pog., ekspr. tri otroke ima na puklu 'skrbeti mora za tri otroke'; pog., ekspr. dobiti jih po puklu 'biti tepen; biti premagan';

F+: imeti na puklu koga, kaj (4 pojavitve): ... je Larisa lahko vesela, da še med tekom ni imela na puklu kakšnega varnostnika.

F+: biti na puklu komu (1 pojavitev): ... posmeh bivšim sodelavcem, ter, da nisem nikomur »na puklu«, torej tudi ne Sloveniji.

$\mathrm{F}+$ : dobiti (jih) po puklu (0 pojavitev).

(1) PULFER -fra m nižje pog. 'smodnik' < srvnem. pulver 'prah' od 14. st. tudi 'smodnik'; nem. Pulver (SES, 593; ESSJ IV, /; ST, 203).

Označen frazeološki pomen v SSKJ:

- nižje pog. ta prav gotovo ne bo iznašel pulfra 'ni posebno pameten, bister'; F+: (izumiti/odkriti/(i)znajti) pulfer (7 pojavitev): Brez očividne namere, da bi na novo izumili pulfer, le toliko, da, naj navedem strokovno bedasti ... - ... in o marsikom smo dejali, da pulfra pa ta glih ne bi znašel. - Verjetno ne bomo izumili pulfra, če rečemo, da je domovina v nasprotju ...

(3) PUTER -tra m nižje pog. '(surovo) maslo' < bair.öster. Putter; mhd. buter; nhd. Butter (ST, 205; ESSJ IV, 139; SES, 596). 
Pogojno manjkajoč • frazeološki pomen v SSKJ, saj prevladuje frazem (F+: kot po maslu (1385 pojavitev)) iti po maslu komu kaj;

$\mathrm{F}+$ : iti/delovati kot po putru (1 pojavitev): ... kjer mora zavoljo številnih členov $v$ verigi vse delovati kot po putru.

\section{Sklep}

Iz tabele je razvidno, da so germanizmi, ki so frazemske sestavine, največkrat označeni s stilno-plastnimi kvalifikatorji (70 \%). Med njima sta najpogostejša kvalifikatorja nižje pogovorno (marela, nucati, ofer, paca, pleh, pukel, pulfer, puter) in pogovorno (mašina, mežnar, nuna, pare, planka), medtem ko je delež časovno-frekvenčnih 20-odstoten in ekspresivnih le 10-odstoten.

Tabela 1: Kvalifikatorske oznake

\begin{tabular}{|c|c|c|c|c|c|c|c|c|c|}
\hline \multirow[t]{2}{*}{ Kvalifikator } & \multicolumn{3}{|c|}{ Stilno-plastni } & \multicolumn{3}{|c|}{ Časovno-frekvenčni } & \multicolumn{3}{|c|}{ Ekspresivni } \\
\hline & $\begin{array}{l}\text { nižje } \\
\text { pog. }\end{array}$ & pog. & žarg. & star. & $\begin{array}{l}\text { raba } \\
\text { peša }\end{array}$ & $\begin{array}{c}\text { nekdaj } \\
\text { oz. } \\
\text { zgod. }\end{array}$ & ekspr. & slabš. & iron. \\
\hline malar & & & + & & & & & & \\
\hline malha & & & & & & + & & & \\
\hline marela & + & & & & & & & & \\
\hline marnja & & & & & & & + & & \\
\hline martra & & & & + & & & & & \\
\hline mašina & & + & & & & & & & \\
\hline mežnar & & + & & & & & & & \\
\hline muja & & & & & + & & & & \\
\hline nucati & + & & & & & & & & \\
\hline nuna & & + & & & & & & & \\
\hline ofer & + & & & & & & & & \\
\hline paca & + & & & & & & & & \\
\hline pankrt & & & & & & & & + & \\
\hline pare & & + & & & & & & & \\
\hline pildek & & & & & & & & & + \\
\hline planka & & + & & & & & & & \\
\hline pleh & + & & & & & & & & \\
\hline pranger & & & & & & + & & & \\
\hline pukel & + & & & & & & & & \\
\hline pulfer & + & & & & & & & & \\
\hline puter & + & & & & & & & & \\
\hline
\end{tabular}

Če zanemarim označeno ekspresivnost, ki je sploh tipična lastnost vseh frazemov v razmerju do njihovih nefrazeoloških ustreznic, potem kaže primerjava med slovarsko kvalifikatorsko oznako germanizma in frazemom z njim 
naslednje. Največja enakost med obema je pri stilno-plastnih oznakah. Pri kar sedmih sta kvalifikatorja namreč prekrivna (navajam le frazeme: glasovalna mašina; jezik nucati, pamet nucati; iti k nunam; imeti koga v paci; skakati čez planke; pleh muzika; ne iznajti pulfra), pri dveh pa je prišlo da premika iz nižje pogovornega v pogovorno (ženi se pod marelo, napet kot marela; imeti kogal kaj na puklu, dobiti jih po puklu).

Pri časovno-frekvenčnih oznaka je prekriven le en primer (božja/bridka martra) in le en primer, ko germanizem z oznako nižje pogovorno nastopi v frazemu, ki je označen starinsko (dati ofer). Dva germanizma z oznako nekdaj in zgodovinsko pa nastopita v pregovoru oz. frazemih, ki nosita le oznako ekspresivno (vsak berač svojo malho hvali; postaviti/dati na pranger).

Velik delež frazemov z germanizmi, ki so označeni z (nižje) pogovorno in katerih živost je večinoma tudi korpusno potrjena, podpira razmislek Erike Kržišnik (2009: 53) v zvezi z mestom frazeologije v novem slovarju slovenskega jezika. Če želimo odgovoriti na vprašanje, kaj v novi slovar, moramo namreč definirati njegovo vrsto:

Če govorimo o večjem (večzvezkovnem) slovarju, je treba v zvezi z vprašanjem, kaj je slovenski (knjižni in/ali) standardni jezik danes, odgovoriti tudi na vprašanje, kaj je »danes«. Ta »danes« namreč zajema generacije rojenih govorcev, starih od vsaj petih do skoraj stotih let. S tega vidika se tudi naslanjanje zgolj na obstoječe korpuse, zlasti to velja za sicer najbolj relevanten korpus FidaPLUS, pokaže kot nezadostno.

/.../ Prednost izbire standardnega jezika pred knjižnim bi se za frazeologijo (zlasti za njen jedrni del, torej t. i. frazeologijo v ožjem smislu) pokazala v večji odprtosti za kvalifikacijo tipa pogovarjalno (prim. kolokvialno). Kvalifikator pogovorno namreč ravno pri frazeološkem gradivu najbolj očitno kaže svojo razpetost med socialnozvrstno in prenosniško vrednostjo.

\section{LITERATURA IN VIRI}

France BEZLAJ, 1977-2007: Etimološki slovar slovenskega jezika I-V. Ljubljana: Založba ZRC.

DUDEN, 22002: Redewendungen. Wörtebuch der deutschen Idiomatik. Band 11. Mannheim.

FIDAPLUS: http://www.fidaplus.net

Željka FINK, Antica MENAC, 2008: Hrvatska frazeologija - staro i novo. Komparacja współczesnych języków słowiańskich. 3Frazeologia. Ur. Walerij Mokijenko in Harry Walter. Opole: Universität Greifswald - Institut für Slawistik in Uniwersytet Opolski - Instytut Filologii Polskiej. 88-100.

Elizabeta JENKO, 1994: Sich auf die Socken machen/vzeti pot pod noge. Deutschslowenisches Wörterbuch der Redewendungen. Celovec.

Monika KALIN GOLOB, 2008: Jezikovnokulturni pristop h knjižni slovenščini. Ljubljana: Fakulteta za družbene vede. 
Janez KEBER, 2003: Frazeološki slovar slovenskega jezika. Poskusni zvezek. Ljubljana: Založba ZRC, ZRC SAZU.

Erika KRŽIŠNIK, 1994: Slovenski glagolski frazemi (ob primeru frazemov govorjenja). Doktorska disertacija. Ljubljana.

- -, 2005: A type of minimal phraseological units characteristic of Slovene. Linguistica letn. 45. 159-172.

--, 2009: Kam in kako s frazeologijo v novem slovarju. Strokovni posvet o novem slovarju slovenskega jezika. Ur. Andrej Perdih. Ljubljana: Založba ZRC, ZRC SAZU. 53-60.

Antica MENAC, 2007: Hrvatska frazeologija. Zagreb: Knjigra. 109-123.

Maks PLETERŠNIK, 2006: Slovensko-nemški slovar. Transliterirana izdaja. Prvi del A-O. Drugi del P-Ž. Ljubljana.

Slovar slovenskega knjižnega jezika z Odzadnjim slovarjem slovenskega jezika in Besediščem slovenskega jezika z oblikoslovnimi podatki: Elektronska izdaja na plošči CD-ROM. Ljubljana 1998.

Slovenski pravopis. 2001. Ur. J. Toporišič. Ljubljana: Založba ZRC, ZRC SAZU.

Marko SNOJ, ${ }^{2} 2003$ : Slovenski etimološki slovar. Ljubljana.

- -, 2006: O tujkah in izposojenkah v slovenskem jeziku. Slavistična revija: Slovensko jezikoslovje danes 54/posebna št., 343-350.

Irena STRAMLJIČ BREZNIK, 2004: Germanizmi v zahodnem slovenskogoriškem podnarečju. Annales, 331-336.

- -, 2007: Samostalniški germanizmi v frazemih Slovarja slovenskega knjižnega jezika od a do h. Besedje slovenskega jezika. Ur. Marko Jesenšek. Maribor: Slavistično društvo Maribor. (Zora 50). 291-303.

,$-- 2007 \mathrm{a}$ : Slovensko besedje v prepletu znotraj- in medjezikovnih razmerij. Besedoslovne spremembe slovenskega jezika skozi čas in prostor. Ur. Marko Jesenšek. Maribor: Slavistično društvo Maribor. (Zora 49). 425-474.

- -, 2009: Pomenski opisi rastlinskih poimenovanj v novem slovarju slovenskega jezika. Strokovni posvet o novem slovarju slovenskega jezika. Ur. Andrej Perdih. Ljubljana: Založba ZRC, ZRC SAZU. 109-118.

Hildegard STRIEDTER-TEMPS, 1963: Deutsche Lehnwörter im Slovenischen. Berlin.

Jože TOPORIŠIČ, 1988: Besedni germanizmi v Trubarjevem Catechismusu. Slavistična revija 36/1, 109-120.

- -, 1992: Enciklopedija slovenskega jezika. Ljubljana: Cankarjeva založba.

--, 1996: Dvojčiči in podobne frazeološke zgradbe v slovenščini. Slavistična revija 44/3, 269-279.

- -, 2000: Slovenska slovnica. Četrta, prenovljena in razširjena izdaja. Maribor: Založba Obzorja Maribor. 
- -, 2006: Prevzete prvine slovenskega knjižnega jezika (Glasovi, pisava, oblika, tvorba, besedje). Besedjeslovne razprave. Ljubljana: Založba ZRC, ZRC SAZU. $62-72$.

\section{GERMANISMS IN IDIOMS INCLUDED IN THE DICTIONARY OF SLOVENE LITERARY LANGUAGE (SSKJ) FROM M TO P}

This article uses the methodology for researching Germanisms used as idioms in the Dictionary of Slovene Literary Language (SSKJ) from A to L and now from M to P. The methodology has been proven successful in terms of (1) recognition of Germanisms in appropriate foreign and native dictionaries; (2) checking to see if the Germanism is a headword in the SSKJ and whether its phraseological use is marked; (3) checking to see if the Germanism is included in the Fidaplus corpus in order to establish its usage in language or to state a new phraseological appearance not marked in the SSKJ.

About 20 headwords recognised as Germanisms have been chosen from the SSKJ and classified into three typical groups:

(1) the idiom(s) are included in the special phraseological description of a dictionary article belonging to the headword:

mašina pog. < nhd. Maschine < franz. machine, lat. machina (ST; 178; ESSJ II,/; SES, 384);

- pog., slabš. glasovalna mašina 'vse, kar v zvezi z volitvami, glasovanjem dela kaka skupina za svojo zmago';

(2) the idiom(s) are/are not included in the special phraseological description of a dictionary article belonging to the headword:

pare par ž mn. pog. 'mrtvaški oder' < ahd.bair. para; ahd. bara; mhd. bare 'Sänfte, Bahre, Totenbahre' (ST, 189; ESSJ IV, 9; SES, 493): položiti na pare; ležati na parah;

(3) the idiom(s) are not included in a dictionary article belonging to the headword at all: mežnar -ja m pog. 'kdor oskrbuje cerkev; cerkovnik' < mhd. mesnaere, messenaere 'Küster' (ST, 179; ESSJ III, 183; SES, 399): stati kot mežnar; 'nedejavno opazovati dogodek, pri katerem bi bila pričakovana, zaželena dejavnost' 